\title{
Fragmentation of microspheres after bronchial artery injection: a case report and review of the literature
}

\author{
Wei Luo ${ }^{1}$, Tongchen $\mathrm{Hu}^{2}$, Yu Mao ${ }^{3}$ and Qi Yu ${ }^{4^{*}}$
}

\begin{abstract}
Background: Massive hemoptysis due to aspergilloma is a rare but life-threatening complication. Bronchial artery embolization is recommended as a definitive treatment for massive hemoptysis. Polyvinyl alcohol is widely used in bronchial artery embolization. A very small number of studies have reported disrupted polyvinyl alcohol, which may cause ectopic embolism.

Case presentation: This case highlights an unusual phenomenon in which polyvinyl alcohol fragments appeared on pathological examination in a 61-year-old man, ethnic Han, with massive hemoptysis caused by aspergilloma for whom bronchial artery embolization failed. Lobectomy was carried out successfully. Hematoxylin and eosin stain provides clear images of polyvinyl alcohol fragments, while alpha-smooth muscle cell actin and cluster of differentiation-34 immunohistochemistry revealed their localization in bronchioles.

Conclusion: Thus far, only two cases of polyvinyl alcohol fragments in the lung have been reported, and the mechanism has not been elucidated. These two cases revealed no counter-indication for the use of polyvinyl alcohol. However, in some cases of off-target embolization causing fatal complications, such as stroke, paraplegia, and myocardial, polyvinyl alcohol fragmentation needs to be taken into consideration.
\end{abstract}

Keywords: Aspergillomas, Massive hemoptysis, Embolization, Polyvinyl alcohol microspheres, Case report

\section{Introduction}

Aspergillomas are mass-like fungus balls that are typically composed of Aspergillus fumigatus, most of which are secondary to structurally abnormal lungs, especially those with preexisting cavities. Their main clinical features are recurrent hemoptysis and different amounts of hemoptysis [1]. Massive hemoptysis due to aspergilloma is a rare but deadly complication, with an estimated mortality as high as $38 \%$ [2]. Bronchial artery embolization (BAE) is recommended as a temporary measure before surgery, or as a definitive treatment for massive

*Correspondence: luobao97@163.com

${ }^{4}$ Department of Pediatric Medicine, The People's Hospital of Leshan, Leshan 614000, Sichuan, People's Republic of China

Full list of author information is available at the end of the article hemoptysis [2]. Polyvinyl alcohol (PVA) is widely used in $\mathrm{BAE}$ for its permanent embolization effect. A very small number of studies have reported disrupted PVA, which may cause ectopic embolism [3].

This case provides unique and clear images of PVA fragments in the lung specimen, which probably provide a new explanation for ectopic embolism.

\section{Case presentation}

Written consent was obtained from our institutional review board and the patient for this case report as well as accompanying images. A 61-year-old man, ethnic Han, presented with massive hemoptysis of nearly $500 \mathrm{~mL}$ of fresh blood. He did not complain of any ongoing respiratory symptoms. His past medical history included pulmonary tuberculosis $(\mathrm{TB})$ with 6 months of standard original author(s) and the source, provide a link to the Creative Commons licence, and indicate if changes were made. The images or other third party material in this article are included in the article's Creative Commons licence, unless indicated otherwise in a credit line to the material. If material is not included in the article's Creative Commons licence and your intended use is not permitted by statutory regulation or exceeds the permitted use, you will need to obtain permission directly from the copyright holder. To view a copy of this licence, visit http://creativecommons.org/licenses/by/4.0/. The Creative Commons Public Domain Dedication waiver (http://creativeco mmons.org/publicdomain/zero/1.0/) applies to the data made available in this article, unless otherwise stated in a credit line to the data. 


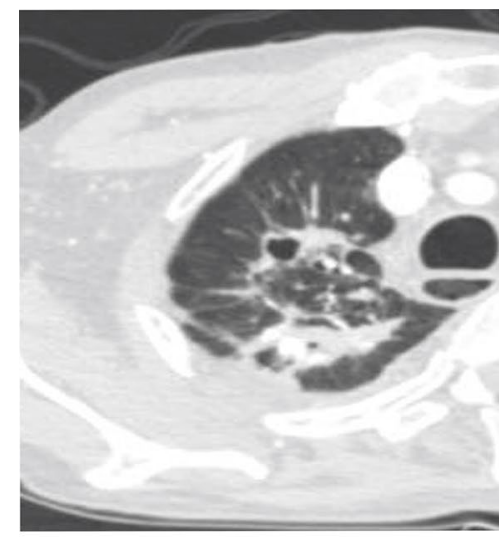

A

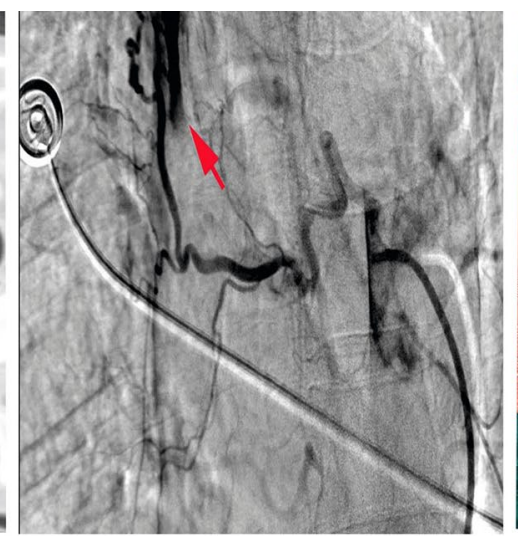

B

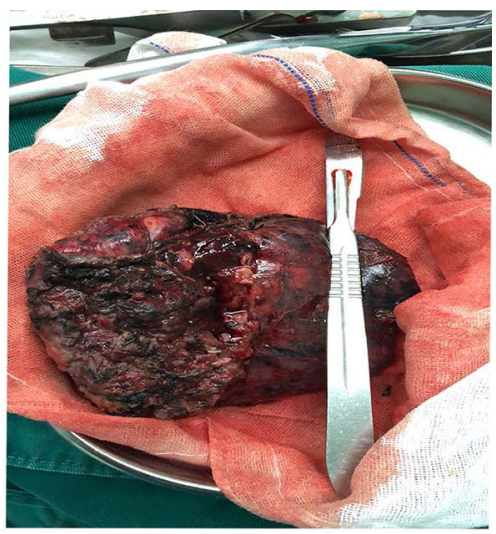

C

Fig. 1 a Chest computerized tomography scan showing bilateral apical post-tuberculosis lung fibrosis and a right apical $2.5 \times 2 \mathrm{~cm}$ thick-walled cavity with a solid intracavity mass bearing the air crescent sign. b Right bronchial artery angiography showing tortuosity, hypertrophy, and extravasation of contrast material into the right upper-lobe bronchus (red arrow). c Gross pathologic specimen after surgical resection of the right lobe

antituberculosis therapy (2HRZE/4HR, 2HRZE: isoniazid $300 \mathrm{mg}$ once daily, rifampin $450 \mathrm{mg}$ once daily, pyrazinamide $750 \mathrm{mg}$ twice daily and ethambutol $750 \mathrm{mg}$ once daily for 2 months; $4 \mathrm{HR}$ : isoniazid $300 \mathrm{mg}$ once daily plus rifampin $450 \mathrm{mg}$ once daily for 4 months), and outpatient follow-up showed resolution of his TB. This patient was a farmer, while social, environmental, family, and psychosocial history was unremarkable. He did not smoke or consume alcohol. The patient had a respiratory rate of 30 breaths/minute and oxygen saturation of $92 \%$ on ambient air. Chest physical examination revealed mild respiratory distress, that is, decreased breath sounds on the top right side of the chest. Other physical examination was unremarkable. Chest computerized tomography scan showed bilateral apical post-tuberculosis lung fibrosis and a right apical $2.5 \times 2 \mathrm{~cm}^{2}$ thick-walled cavity with a solid intracavity mass bearing the air crescent sign, while enhanced computerized tomography (CT) scan indicated remarkable enhancement around the lesion and no obvious fistula. (Fig. 1a). BAE was carried out, and digitally subtracted angiography demonstrated that the right bronchial arteries were abnormal, with tortuosity, hypertrophy, and extravasation of contrast material into the right bronchus (Fig. 1b). Because of the tortuosity of bronchial artery, the microcatheter could not be reliably and stably imported; thus, steel platinum coils were not an option. One gram of PVA microspheres (Hegui, China) with a diameter of 700-900 $\mu \mathrm{m}$ were chosen to embolize the culprit bronchial artery. However, the embolic agents appeared quickly in the right upperlobe bronchus after slow and gentle injection into the bronchial artery. Rapid deterioration during the procedure, including ongoing hemoptysis, tachycardia, and hypotension, necessitated surgical resection of the right upper lobe (Fig. 1c). Pathological examination demonstrated not only septate hyphae in a resected cavity with a chronic inflammatory reaction (Fig. 2a) but also a basophilic-appearing PVA fragment in the lung (Fig. 2b, c). After several days of stay in the intensive care unit, the patient, lacking any symptoms of hemoptysis and ectopic embolism, was transferred to a normal ward and discharged 2 weeks later. This patient received $1600 \mathrm{~mL}$ suspended erythrocyte and $1600 \mathrm{~mL}$ plasma transfusion during hospitalization. One month later, outpatient follow-up showed good recovery except a little bit of right chest pain. Figure 3 is a timeline demonstrating the important dates for the patient in hospital and on outpatient follow-up.

\section{Discussion}

PVA has been widely used in BAE for treatment of massive hemoptysis for its permanent embolization effect and relative easy drug-delivery access (no need for microcatheter) compared with gelatin sponge particles and stainless steel platinum coils. In this case, PVA was chosen in the hope of occluding the fistulas. With the accumulation of PVA with contrast material, the shape of the right main bronchi was clear; therefore, surgical resection was carried out. Pathologic examination demonstrated PVA fragments. Alpha-smooth muscle cell actin (Alpha-SMA) and CD34 immunohistochemistry was carried to locate the fragments. To the best of our knowledge, few cases have reported images of disrupted PVA in the human lung [3, 4].

A systematic search of MEDLINE and EMBASE was conducted from inception to 25 July 2021, using the 

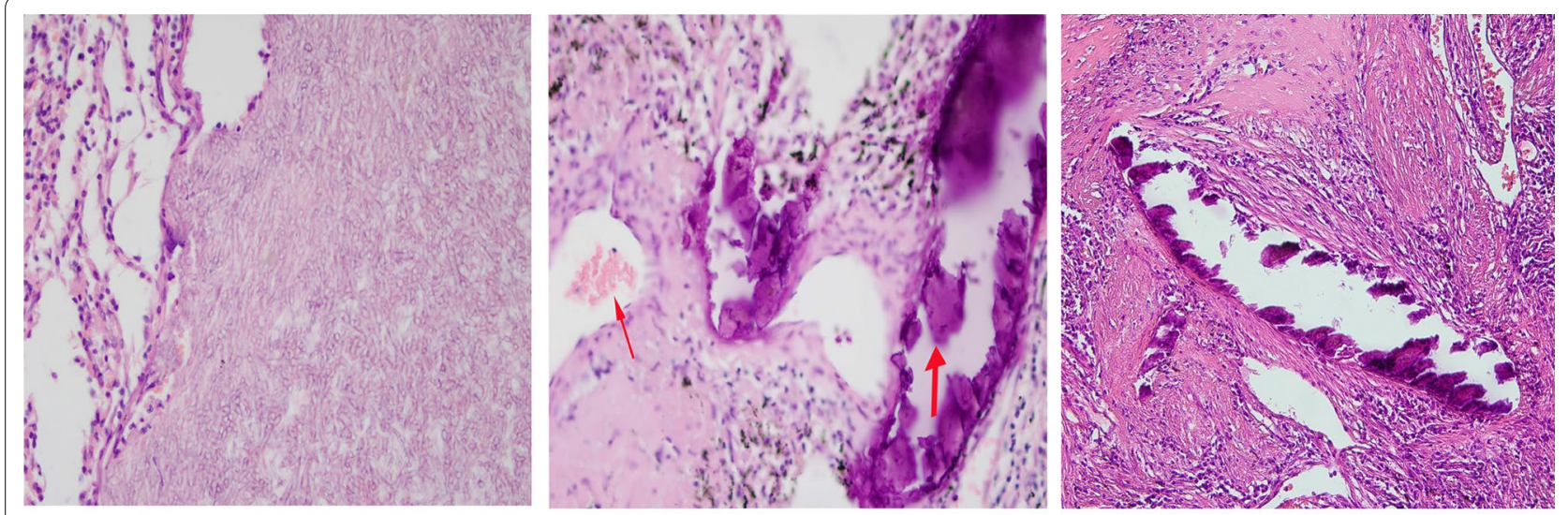

A

D

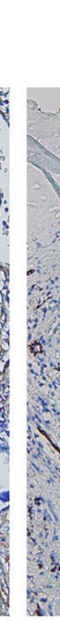

更

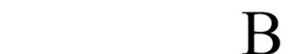

B

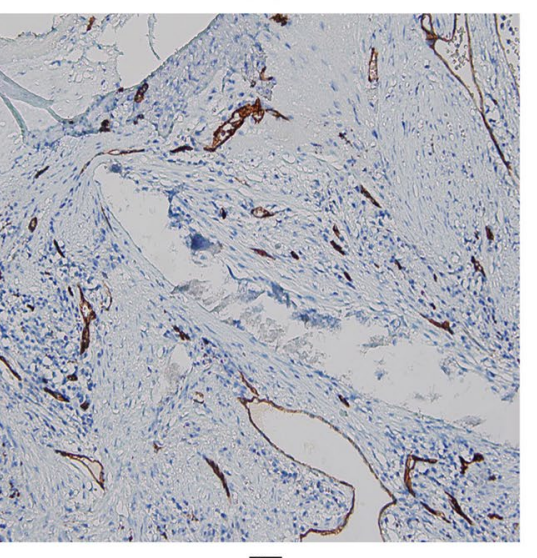

E

Fig. 2 a Septate hyphae in a resected cavity with a chronic inflammatory reaction. Hematoxylin and eosin (H\&E) staining, original magnification $\times 400$. $\mathbf{b}$ Basophilic-appearing PVA fragment (thick arrow) and red blood cells in the lung (thin arrow). H\&E staining, original magnification $\times 400$. $\mathbf{c}$ Basophilic-appearing PVA fragment. H\&E staining, original magnification $\times 200$. d Alpha-SMA immunohistochemistry showing the fragments were not in the vessel but in the bronchioles, original magnification $\times 200$. e CD34 immunohistochemistry showing the fragments were not in the vessel but in the bronchioles, original magnification $\times 200$

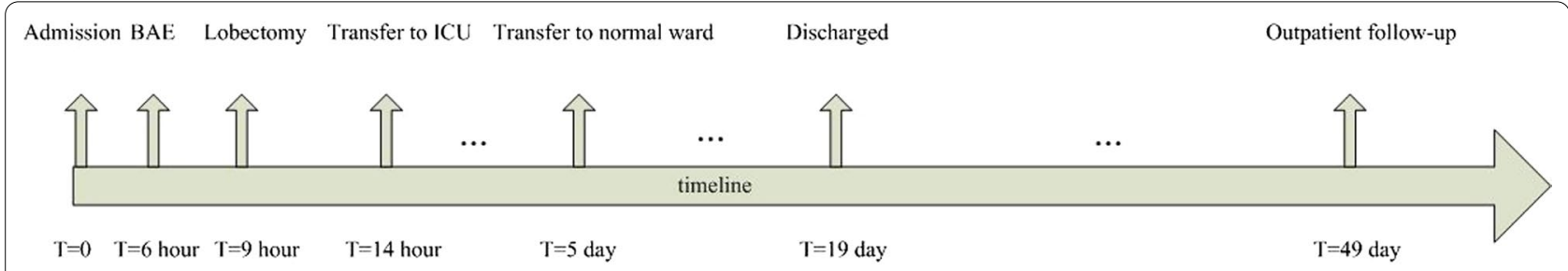

Fig. 3 Timeline demonstrating important dates for the patient in hospital and on outpatient follow-up

search terms "PVA AND bronchial artery embolism," "massive hemoptysis AND bronchial artery embolism," "massive hemoptysis AND PVA AND bronchial artery embolism," "massive hemoptysis AND aspergillomas AND PVA AND Bronchial artery embolism." Only two reports were found (Table 1). Robbins and colleagues reported that microsphere fragments appeared in the lung vessels, while Bonnefoy et al. also captured images of particles in the lungs $[4,5]$.

As can be seen in Fig. 2d, e, the fragments were not in the vessel but in the bronchioles. This could be explained 
Table 1 Reports of microsphere images in the lung

\begin{tabular}{lllll}
\hline Publishing year & Patient's disease & Receive BAE & Embolic agent & $\begin{array}{c}\text { Emerging } \\
\text { PVA } \\
\text { fragments }\end{array}$ \\
\hline 2015 & Chronic pulmonary thromboembolic & Yes & PVA & Yes \\
2018 & $\begin{array}{l}\text { disease } \\
\text { Bronchial Dieulafoy disease }\end{array}$ & Yes & PVA & Not sure \\
Present case & Aspergillomas & Yes & PVA & Yes \\
\hline
\end{tabular}

PVA Polyvinyl alcohol

by the fistula between bronchial artery and the bronchioles. Of interest to us was the size of the PVA fragments, which scattered around the bronchioles with different diameters. Some of the fragments were just as large as the red blood cells (Fig. 2b). This phenomenon raises the question of whether the PVA fragmentation occurred during specimen preparation or in the human body or associating with TB or Aspergillus. For the first possibility, our slice thickness was $5 \mu \mathrm{m}$, while PVA exceeding this thickness would be expected to break during histological preparation. We are more curious about the latter possibility. As Fig. 2b, c shows, the contour of the PVA fragments is not clear and lacks a cutting edge, while many small fragments of different sizes are scattered in the vessel. The mechanism of PVA fragmentation in vivo was not clear, though it may be related to the mechanical force of injection. However, we used a 5F Cobra angiography catheter (Terumo, Japan) with $1.65 \mathrm{~mm}$ inner diameter, which is much larger than $900 \mu \mathrm{m}$ of largest PVA size, so this probability is very low. We could exclude the possibility that PVA fragmentation was associated with TB or Aspergillus according to the pathological features. The PVA fragmentation appeared in the bronchioles, and this is cause for great concern, because embolic agents smaller than $50 \mu \mathrm{m}$ might pass through the physiological arteriovenous shunt to the systemic arteries, resulting in ectopic embolisms [6]. In fact, there are several reported cases of off-target embolization causing stroke, though we were not convinced by some of the proposed mechanisms. In these cases, there was no presence of collateral circulation, no visible shunt, and no known mechanisms proposed by Knight [7], but the strokes happened after BAE $[8,9]$. The authors hypothesized that the microspheres probably passed through an unvisualized right-to-left shunt from the right pulmonary arteries to the right pulmonary veins or created a thrombus during the procedure, dropping into the vertebral artery and causing an embolic stroke $[8,9]$. Moreover, we also observed a stroke during the procedure of drug-eluting bead bronchial arterial chemoembolization in a lung cancer patient. Although we proposed that mechanical forces disrupted the unvisualized anastomoses, which opened errant emboli passages through the pulmonary vein and allowed off-target embolization of the intracranial arteries [10], we could not rule out the possibility of PVA fragmentation.

\section{Conclusions}

This case raised a concern about the safety of PVA when applied in humans. Thus far, only two cases have reported the fragmentation of PVA, and the mechanism has not been elucidated. We could not make any conclusion based on the two cases. Moreover, there are tens of thousands of cases treated successfully with PVA every year, so this does not contradict the use of PVA. However, in some cases of off-target embolization causing fatal complication, such as stroke, paraplegia, and myocardial, PVA fragmentation needs to be taken into consideration.

\section{Abbreviations}

BAE: Bronchial artery embolization; PVA: Polyvinyl alcohol; TB: Tuberculosis; CT: Computerized tomography; Alpha-SMA: Alpha-smooth muscle cell actin.

\section{Acknowledgements}

Not applicable.

\section{Authors' contributions}

WL and QY worked together for the treatment of this patient and preparation of the manuscript. DTH performed the surgery. YM is the pathologist. All authors read and approved the final manuscript.

Funding

There is no funding support for this case.

Availability of data and materials

All data and materials are available.

\section{Declarations}

Ethics approval and consent to participate

Approval was obtained from our institutional review board and patient for this case report.

\section{Consent for publication}

Written informed consent was obtained from the patient for publication of this case report and any accompanying images. A copy of the written consent is available for review by the Editor-in-Chief of this journal.

Competing interests

All authors declare no conflicts of interest. 


\section{Author details}

'Department of Respiratory and Critical Care Medicine, The People's Hospital of Leshan, Leshan 614000, Sichuan, People's Republic of China. ${ }^{2}$ Department of Thoracic Surgery, The People's Hospital of Leshan, Leshan 614000, Sichuan, People's Republic of China. ${ }^{3}$ Department of Pathology, The People's Hospital of Leshan, Leshan 614000, Sichuan, People's Republic of China. ${ }^{4}$ Department of Pediatric Medicine, The People's Hospital of Leshan, Leshan 614000, Sichuan, People's Republic of China.

Received: 6 April 2021 Accepted: 7 September 2021

Published online: 26 October 2021

\section{References}

1. Denning DW, Cadranel J, Beigelman-Aubry C, Ader F, Chakrabarti A, Blot S, Ullmann AJ, Dimopoulos G, Lange C. Chronic pulmonary aspergillosis: rationale and clinical guidelines for diagnosis and management. Eur Respir J. 2016;47(1):45-68.

2. Hirshberg B, Biran I, Glazer M, et al. Hemoptysis: etiology, evaluation, and outcome in a tertiary referral hospital. Chest. 1997;112:440-4.

3. Lorenz J, Sheth D, Patel J. Bronchial artery embolization. Semin Intervent Radiol. 2012;29(3):155-60.

4. Robbins IM, Johnson J, Petracek M, Lambright E, Bream P, Merantz S, Pugh ME, Hemnes AR. Translocation of microspheres into the pulmonary artery after bronchial artery injection. Am J Respir Crit Care Med. 2015;191(12):201412-2325IM.

5. Bonnefoy V, Garnier M, Tavolaro S, Antoine M, Assouad J, Fartoukh M, Gibelin A. Bronchial Dieulafoy's disease: visualization of embolization particles in bronchial aspirate. Am J Respir Crit Care Med. 2018;198(7):954-5.

6. Hoffman JI. Normal and abnormal pulmonary arteriovenous shunting: occurrence and mechanisms. Cardiol Young. 2013;23(5):629-41.

7. Pestana Knight EM, Novelli PM, Joshi SM. Cerebral and systemic infarcts after bronchial artery embolization. Pediatr Neurol. 2011:45:324-7. https://doi.org/10.1016/j.pediatrneurol.2011.08.012.

8. Hoffman M, Gerding JP, Zuckerman JB. Stroke and myocardial infarction following bronchial artery embolization in a cystic fibrosis patient. J Cyst Fibros. 2017;16(1):161-2.

9. Park JH, Kim DS, Kwon JS, Hwang DH. Posterior circulation stroke after bronchial artery embolization. Neurol Sci. 2012;33(4):923-6.

10. Luo W, Wei MG, Wei HL, Li YL. Cerebral infarction after drug-eluting bead bronchial arterial chemoembolization due to the mechanical force-mediated opening of an errant passage. Chin Med J (Engl). 2020;134(8):989-90.

\section{Publisher's Note}

Springer Nature remains neutral with regard to jurisdictional claims in published maps and institutional affiliations.
Ready to submit your research? Choose BMC and benefit from:

- fast, convenient online submission

- thorough peer review by experienced researchers in your field

- rapid publication on acceptance

- support for research data, including large and complex data types

- gold Open Access which fosters wider collaboration and increased citations

- maximum visibility for your research: over 100M website views per year

At BMC, research is always in progress.

Learn more biomedcentral.com/submissions 